\title{
Prevalence of Low Back Pain among Physical Therapists in Kuwait
}

\author{
Dia Shehab $^{a}$ Khalid Al-Jarallah ${ }^{a}$ Mohamed A.A. Moussa ${ }^{b}$ Nihad Adham ${ }^{c}$ \\ Departments of a Medicine and ${ }^{b}$ Community Medicine, Faculty of Medicine, Kuwait University, and \\ 'Mubarak Al-Kabeer Hospital, Kuwait
}

\section{Key Words}

Low back pain - Epidemiology · Prevalence .

Physical therapist $\cdot$ Risk factors

\begin{abstract}
Objective: To determine the life and point prevalence rates and study the characteristics of work-related and non-work-related low back pain (LBP) among physical therapists in Kuwait and its effect on their regular activities. Subjects and Methods: A specially designed selfadministered questionnaire was distributed to 143 physical therapists in Kuwait. The questionnaire included demographic data, history and characteristics of LBP before and after working as a physical therapist, the effect of LBP on regular activities and current LBP. A visual analogue scale was used to score the intensity of the pain. Results: One hundred (70\%) of the 143 physical therapists completed the questionnaire; mean age and standard deviation of the respondents were $35.9 \pm 8.45$ years. The lifetime prevalence of work-related LBP was $70 \%(61.8 \%$ in males and $74.2 \%$ in females $)$ and the point (current) prevalence rate was $57 \%(31.6 \%$ in males and $68.4 \%$ in females). All the 100 therapists were college graduates who worked full-time and $82 \%$ were employed in general hospitals and rehabilitation centers. The most common areas of specialty were orthopedics $(32 \%)$ and neurology (23\%). Fifty percent reported that LBP affected their regular activities, $28.6 \%$ reported limitation due to pain and $11.4 \%$ changed their work settings because of LBP. The main site of pain was at low back
\end{abstract}

\section{KARGER}

Fax + 41613061234

E-Mail karger@karger.ch

www.karger.com
(C) 2003 S. Karger AG, Basel

1011-7571/03/0124-0224\$19.50/0

Accessible online at:

www. karger.com/mpp and buttocks. Pain intensity was scored similarly among male and female physical therapists. Conclusion: Workrelated and point prevalence rates of LBP among physical therapists in Kuwait are high and affect their daily activities, necessitating changes in work settings.

Copyright $\odot 2003$ S. Karger AG, Basel

\section{Introduction}

Lumbar pain, generally referred to as low back pain (LBP), is among the most common medical problems in the western industrialized countries. It has been estimated that $50-80 \%$ of the adult population suffer to a significant extent from LBP at some point in life [1-7]. In general, although back pain does not discriminate among gender, race or work environment, some professions are more susceptible than others to LBP $[5,8]$. Physical therapists are among the susceptible groups due to frequent practice of lifting, bending, stooping, twisting, turning, prolonged sitting or standing [3, 9-12]. In Edmonton, Canada, Mierzejewski et al. [13] reported a high lifetime prevalence of LBP among physical therapists, $49.2 \%$ of which is work-related. In California, USA, Molumphy et al. [14] reported that $29 \%$ of physical therapists experienced work-related back pain and 58\% of the initial episodes occurred during the first 4 years of working as a physical therapist.

No data have been reported about the prevalence of LBP among physical therapists in Kuwait. Hence we decided to undertake this study. The objective was to
Dr. Dia Shehab, FRCPC, FACR

Department of Medicine

Faculty of Medicine, Kuwait University

PO Box 24923, Safat 13110 (Kuwait)

Tel. +965 5319596, Fax +965 5338907, E-Mail diaa@hsc.kuniv.edu.kw 
Table 1. Age and professional experience of physical therapists (n, \%)

\begin{tabular}{|c|c|c|c|c|c|c|c|c|}
\hline & \multicolumn{3}{|c|}{ Work-related LBP } & \multicolumn{3}{|c|}{ Non-work-related LBP } & \multicolumn{2}{|l|}{ Total } \\
\hline & M & $\mathrm{F}$ & subtotal & M & $\mathrm{F}$ & subtotal & M & $\mathrm{F}$ \\
\hline \multicolumn{9}{|c|}{ Age group, years } \\
\hline $21-25$ & $0 \quad(0)$ & $6(12)$ & $6(9)$ & $0 \quad(0)$ & $4(24)$ & $4(13)$ & $0 \quad(0)$ & $10(15)$ \\
\hline $26-30$ & $2(10)$ & $19(39)$ & $21(30)$ & $2(15)$ & $3(18)$ & $5(17)$ & $4(12)$ & $12(18)$ \\
\hline $31-35$ & $1(5)$ & $9(18)$ & $10(14)$ & $1(8)$ & $3(18)$ & $4(13)$ & $2(6)$ & $12(18)$ \\
\hline $36-40$ & $6(28)$ & $6(12)$ & $12(17)$ & $4(31)$ & $3(18)$ & $7(23)$ & $10(29)$ & $9(14)$ \\
\hline $41-45$ & $9(43)$ & $7(14)$ & $16(23)$ & $2(15)$ & $3(18)$ & $5(17)$ & $11(32)$ & $10(15)$ \\
\hline $46-50$ & $2(10)$ & $0 \quad(0)$ & $2(3)$ & $2(15)$ & $1(6)$ & $3(10)$ & $4(12)$ & $1(1.5)$ \\
\hline $51-55$ & $0 \quad(0)$ & $2(4)$ & $2(3)$ & $1(8)$ & $0 \quad(0)$ & $1(3)$ & $1(3)$ & $2(3)$ \\
\hline$>55$ & $1(5)$ & $0 \quad(0)$ & $1(1.4)$ & $1(8)$ & $0 \quad(0)$ & $1(3)$ & $2(6)$ & $0 \quad(0)$ \\
\hline \multicolumn{9}{|c|}{ Current job duration, years } \\
\hline$<5$ & $3(14)$ & $18(37)$ & $21(30)$ & $2(15)$ & $7(54)$ & $9(32)$ & $5(15)$ & $25(38)$ \\
\hline $5-9$ & $2(10)$ & $19(39)$ & $21(30)$ & $6(46)$ & $2(13)$ & $8(29)$ & $8(24)$ & $21(32)$ \\
\hline $10-14$ & $3(14)$ & $5(10)$ & $8(11)$ & $0(0)$ & $2(13)$ & $2(7)$ & $3(9)$ & $7(11)$ \\
\hline $15-19$ & $8(38)$ & $4(8)$ & $12(17)$ & $3(23)$ & $2(13)$ & $5(18)$ & $11(32)$ & $6(9)$ \\
\hline$>19$ & $4(19)$ & $3(6)$ & $7(10)$ & $2(15)$ & $2(13)$ & $4(14)$ & $6(18)$ & $5(8)$ \\
\hline \multicolumn{9}{|c|}{ Years of experience as a physical therapist } \\
\hline$<10$ & $3(14)$ & $29(62)$ & $32(46)$ & $4(31)$ & $6(35)$ & $10(33)$ & $7(21)$ & $35(53)$ \\
\hline $10-19$ & $8(38)$ & $13(13)$ & $21(30)$ & $4(31)$ & $6(35)$ & $10(33)$ & $12(35)$ & $19(29)$ \\
\hline$>19$ & $10(48)$ & $7(14)$ & $17(24)$ & $5(38)$ & $4(24)$ & $9(30)$ & $15(44)$ & $11(17)$ \\
\hline \multicolumn{9}{|c|}{ Direct patient contact per week, hours } \\
\hline$<10$ & $1(5)$ & $0 \quad(0)$ & $1(1.4)$ & $1(8)$ & $0 \quad(0)$ & $1 \quad(3)$ & $2(6)$ & $0 \quad(0)$ \\
\hline $10-19$ & $1(5)$ & $1(2)$ & $2(3)$ & $0 \quad(0)$ & $0(0)$ & $0(0)$ & $1(3)$ & $1(1.5)$ \\
\hline $20-29$ & $9(43)$ & $20(41)$ & $29(41)$ & $0 \quad(0)$ & $2(12)$ & 2 (7) & $9(26)$ & $22(33)$ \\
\hline $30-39$ & $6(28)$ & $18(37)$ & $24(34)$ & $9(69)$ & $8(47)$ & $17(57)$ & $15(44)$ & $26(39)$ \\
\hline$>39$ & $4(19)$ & $10(21)$ & $14(20)$ & $3(23)$ & $7(41)$ & $10(33)$ & $7(21)$ & $17(26)$ \\
\hline
\end{tabular}

determine lifetime prevalence of work-related LBP and point prevalence among physical therapists in Kuwait, and to investigate the effect of LBP on their daily activities.

\section{Subjects and Methods}

A self-administered questionnaire (Appendix 1) was used for data collection. The questionnaire was piloted initially among 10 physical therapists and no major modifications were needed. The questionnaire included demographic data, history of LBP before and after working as a physical therapist, e.g. onset of pain or injury, duration of LBP episodes, work setting and effect of LBP on daily activities, limitations due to LBP, as well as the presence of current LBP and rating the intensity of LBP on a scale of 0 (no pain) to 10 ( maximum pain) that represented a numerical system of $10 \mathrm{~cm}$ on a visual analogue scale.

The questionnaire was distributed to 143 physical therapists in different clinical settings: hospitals, clinics, schools and community care. Personal and professional characteristics were used to compare the experience of work-related and non-work-related LBP according to gender.

Low Back Pain among Physical Therapists in Kuwait

\section{Data Analysis}

Data were processed using the Statistical Package for Social Sciences (SPSS) computer software. Differences were considered significant if $p$ value was $\leq 0.05$. The Pearson chi-square test was used to assess the extent of association between two categorical variables. In case of skewed non-normal variables like rating score, the median, 2.5th and 97.5th percentiles were used as measures of location and variation, and the Mann-Whitney U nonparametric test was used to assess the significance of the difference between two quantitative variables.

\section{Results}

Of the 143 physical therapists, 100 who are college graduates ( 34 males, 66 females) responded to the questionnaire. The mean age of responding physical therapists was $35.9 \pm 8.5$ years ( $23-58$ years) (table 1$)$. The age distribution is similar in both work-related and non-workrelated groups. Sixty-four percent of participating physical therapists had been in their current position for less than 10 years (mean $9.7 \pm 8.5$ years). With respect to duration of experience as a physical therapist $83 \%$ re- 
Table 2. Basic data and LBP characteristics among responding physical therapists (n, \%) according to gender and work relation

\begin{tabular}{|c|c|c|c|c|c|c|c|c|}
\hline & \multicolumn{3}{|c|}{ Work-related LBP } & \multicolumn{3}{|c|}{ Non-work-related LBP } & \multicolumn{2}{|l|}{ Total } \\
\hline & $\begin{array}{l}M \\
(n=21)\end{array}$ & $\begin{array}{l}F \\
(n=49)\end{array}$ & $\begin{array}{l}\text { subtotal } \\
(\mathrm{n}=70)\end{array}$ & $\begin{array}{l}M \\
(n=13)\end{array}$ & $\begin{array}{l}\mathrm{F} \\
(\mathrm{n}=17)\end{array}$ & $\begin{array}{l}\text { subtotal } \\
(\mathrm{n}=30)\end{array}$ & $\begin{array}{l}M \\
(\mathrm{n}=34)\end{array}$ & $\begin{array}{l}\mathrm{F} \\
(\mathrm{n}=66)\end{array}$ \\
\hline \multicolumn{9}{|l|}{ Speciality } \\
\hline General & $6(28)$ & $8(16)$ & $14(20)$ & $8 \quad(62)$ & $3(18)$ & 11 & $14(41)$ & $11(16.6)$ \\
\hline Neurology & $6(28)$ & $11(22)$ & $17(24)$ & $2(15)$ & $4 \quad(24)$ & $6(20)$ & $8(23.5)$ & $15(23)$ \\
\hline Orthopedic & $6(28)$ & $18(37)$ & $24(34)$ & $3(23)$ & $5 \quad(29)$ & $8 \quad(27)$ & $9(26.4)$ & $23(35)$ \\
\hline Burns/plastic & $1(5)$ & $1(2)$ & $2(3)$ & $0 \quad(0)$ & $0 \quad(0)$ & $0 \quad(0)$ & $1(3)$ & $1(1.5)$ \\
\hline Geriatric & $1(5)$ & $0 \quad(0)$ & $1 \quad(1.4)$ & $(0)$ & $1 \quad(6)$ & $1 \quad(3)$ & 1 (3) & 1 (1.5) \\
\hline Pediatrics & $1(5)$ & $9(18)$ & $10(14)$ & (0) & 3 (18) & $3(10)$ & $1(3)$ & $12(18)$ \\
\hline Cardiac & $0 \quad(0)$ & $2(4)$ & $2(3)$ & $(0)$ & $0 \quad(0)$ & $0 \quad(0)$ & $0 \quad(0)$ & $2(3)$ \\
\hline \multicolumn{9}{|l|}{ Work setting } \\
\hline General hospital & $9(43)$ & $22(45)$ & $31(44)$ & $6(46)$ & $4 \quad(24)$ & 10 & $15(44)$ & $26(39)$ \\
\hline Rehabilitation center & $10(48)$ & $19(39)$ & $29(41)$ & $7 \quad(54)$ & $6(35)$ & $13(43)$ & $16(47)$ & $25(38)$ \\
\hline Private hospital & $1(5)$ & $1(2)$ & $2(3)$ & $0 \quad(0)$ & $2(12)$ & $2(7)$ & $1(3)$ & $3(4.5)$ \\
\hline Special school & 1 (5) & $6(12)$ & $7(10)$ & $(0)$ & $3(18)$ & $3(10)$ & $1(3)$ & $9(13.6)$ \\
\hline Community care & $0 \quad(0)$ & $0 \quad(0)$ & $0 \quad(0)$ & $(0)$ & $1 \quad(6)$ & 1 (3) & $0 \quad(0)$ & $1(1.5)$ \\
\hline \multicolumn{9}{|c|}{ Physical disability before $L B P$} \\
\hline None & $16(76)$ & $37(76)$ & $53(76)$ & $13(100)$ & $14(82)$ & $27(90)$ & $29(85)$ & $51(77)$ \\
\hline Musculoskeletal & $5(24)$ & $11(22)$ & $16(23)$ & $0 \quad(0)$ & 3 (18) & $3(10)$ & $5(15)$ & $14(21)$ \\
\hline Neurological & $0(0)$ & $1(2)$ & $1(1.4)$ & $(0)$ & $0 \quad(0)$ & $0 \quad(0)$ & $0 \quad(0)$ & $1(1.5)$ \\
\hline \multicolumn{9}{|c|}{ Type of LBP before working as physical therapist } \\
\hline None & $16(76)$ & $35(71)$ & $51(73)$ & $13(100)$ & $17(100)$ & $30(100)$ & $29(85)$ & $52(79)$ \\
\hline Mild & $4(19)$ & $13(27)$ & $17(24)$ & $0 \quad(0)$ & $0 \quad(0)$ & $0 \quad(0)$ & $4(12)$ & $13(19.6)$ \\
\hline Moderate & $1(5)$ & $1(2)$ & $2(3)$ & $(0)$ & $(0)$ & $(0)$ & $1(3)$ & $1(1.5)$ \\
\hline \multicolumn{9}{|c|}{ Functional limitations before working as physical therapist } \\
\hline None & $17(80)$ & $41(84)$ & $58(83)$ & $13(100)$ & $16(94)$ & $19(94)$ & $30(88.2)$ & $57(86)$ \\
\hline Mild & $2(10)$ & $8(16)$ & $10(14)$ & $0 \quad(0)$ & 1 (6) & $1 \quad(6)$ & $2(6)$ & $9(13.6)$ \\
\hline Moderate & $2(10)$ & $0 \quad(0)$ & $2(3)$ & (0) & (0) & (0) & $2(6)$ & $0 \quad(0)$ \\
\hline
\end{tabular}

Frequencies do not always add to the total due to missings. $\mathrm{M}=$ Male; $\mathrm{F}=$ Female.

ported less than 20 years, with a mean of $12.5 \pm 8.3$ years. The physical therapists with work-related LBP reported direct patient contact of $30-40 \mathrm{~h}$ with a mean of $33.1 \pm$ $16.4 \mathrm{~h}$ per week. The main employers were general hospitals (41\%), rehabilitation centers (41\%) and special education schools (10\%). Fifty-seven of the 100 physical therapists (18 males and 39 females) reported current LBP leading to a point prevalence rate of $57 \%$ (31.6\% in males and $68.4 \%$ in females). The lifetime prevalence of workrelated LBP was $70 \%$ (61.8\% in males, $74.2 \%$ in females). In general, more females than males reported LBP.

The most common areas of specialty with work-related LBP were orthopedics $(\mathrm{n}=24,34 \%)$ and neurology $(\mathrm{n}=$ $17,24 \%)$, while 'general' accounted for the most nonwork-related LBP $(\mathrm{n}=11,37 \%)$. Most female physical therapists $(n=23,35 \%)$ reported orthopedics as their area of specialty, while males $(n=14,41 \%)$ reported their specialty as 'general' (table 2).
The distribution of work settings among those with and without work-related LBP was fairly similar (table 1). However more females than males worked at the special education schools. Physical disability before having LBP was mainly musculoskeletal in both females and males, but it was higher among those with work-related $(23 \%)$ than in those without work-related LBP (10\%). Moreover, females $(21 \%)$ reported higher musculoskeletal disability than males (15\%). Of the 17 (13\%) with work-related LBP before entering the profession, $76.5 \%$ were females; $14 \%$ of them reported mild functional limitations in their daily activities before entering the profession.

Among those with work-related LBP (table 3), 37 (52.8\%) reported mild LBP, 41 (58\%) chronic LBP, 45 $(64 \%)$ duration of 1 week, and in $60(86 \%)$ of the physical therapists with LBP, injury occurred mainly in hospital settings. Further 54.3\% reported impact of LBP on their regular activities due mostly to lifting and carrying 
Table 3. Characteristics of work-related LBP among physical therapists (n, \%)

\begin{tabular}{|c|c|c|c|c|}
\hline & $\begin{array}{l}M \\
(n=21)\end{array}$ & $\begin{array}{l}F \\
(n=49)\end{array}$ & $\mathrm{p}$ value* & Total \\
\hline \multicolumn{5}{|l|}{ Type of LBP } \\
\hline Mild & $12(57)$ & $25(51)$ & \multirow[t]{3}{*}{ NS } & $37(53)$ \\
\hline Moderate & $9(43)$ & $23(47)$ & & $32(46)$ \\
\hline Severe & $0 \quad(0)$ & $1(2)$ & & $1(1.4)$ \\
\hline \multicolumn{5}{|l|}{ Onset of LBP } \\
\hline Acute & $9(43)$ & $20(41)$ & \multirow[t]{2}{*}{ NS } & $29(41)$ \\
\hline Chronic & $12(57)$ & $29(59)$ & & $41(58)$ \\
\hline \multicolumn{5}{|l|}{ Duration of LBP } \\
\hline$<1$ week & $1(5)$ & $0 \quad(0)$ & \multirow[t]{4}{*}{ NS } & $1(1.4)$ \\
\hline 1 week & $14(67)$ & $31(63)$ & & $45(64)$ \\
\hline 2-4 weeks & $5(24)$ & $15(31)$ & & $20(29)$ \\
\hline$>4$ weeks & $0 \quad(0)$ & $1(2)$ & & $1(1.4)$ \\
\hline \multicolumn{5}{|l|}{ Work setting in which injury occurred } \\
\hline Hospital & $19(90)$ & $41(84)$ & \multirow[t]{4}{*}{ NS } & $60(86)$ \\
\hline University & $0(0)$ & $2(4)$ & & $2(3)$ \\
\hline Special school & $1(5)$ & $5(10)$ & & $6(9)$ \\
\hline Community care & $1(5)$ & $1(2)$ & & $2(2.8)$ \\
\hline \multicolumn{5}{|l|}{ Effect of LBP on regular activities } \\
\hline No & $11(52)$ & $21(43)$ & \multirow[t]{2}{*}{ NS } & $32(46)$ \\
\hline Yes & $10(48)$ & $28(57)$ & & $38(54)$ \\
\hline \multicolumn{5}{|l|}{ Activities during LBP injury } \\
\hline None & $9(43)$ & $19(39)$ & \multirow[t]{6}{*}{ NS } & $28(40)$ \\
\hline Lifting, carrying & $8(38)$ & $8(16)$ & & $16(23)$ \\
\hline Pulling, pushing & $0 \quad(0)$ & $2(4)$ & & $2(3)$ \\
\hline Patient handling & $2(10)$ & $6(12)$ & & $8(11.4)$ \\
\hline Prolonged sitting & $1(5)$ & $4(8)$ & & $5(7)$ \\
\hline Prolonged standing & $1(5)$ & $8(16)$ & & $9(13)$ \\
\hline \multicolumn{5}{|l|}{ Limitations due to LBP } \\
\hline No limitation & $1(5)$ & $2(4)$ & \multirow[t]{7}{*}{0.029} & $3(4.3)$ \\
\hline Sick leave & $5(24)$ & $10(20)$ & & $15(21)$ \\
\hline Compensation & $0(0)$ & $11(22)$ & & $11(16)$ \\
\hline Decreased non-work activities & $9(43)$ & $11(22)$ & & $20(29)$ \\
\hline Decreased number of working hours & $3(14)$ & $1(2)$ & & $4(6)$ \\
\hline Change of work setting & $2(10)$ & $6(12)$ & & $8(11.4)$ \\
\hline Others & $0(0)$ & $7(14)$ & & $7(10)$ \\
\hline $\begin{array}{l}\text { Pain score } \\
\text { Median (2-5th, } 97.5 \text { th percentiles) }\end{array}$ & $4(0-10)$ & $5(0-8)$ & NS** & \\
\hline
\end{tabular}

* Chi-square test: categories with low frequency were pooled. ${ }^{* *}$ Mann-Whitney U test. NS $=$ Not significant.
$(22.9 \%)$ as the major activity precipitating the work-related LBP. Decreased non-work activities (28.6\%) such as activities outside work setting like shopping or home duties were the most frequently described limitation due to work-related LBP. The severity of back discomfort required $8(11.4 \%)$ of the therapists to change their work setting. Work-related LBP was not significant between male and female physical therapists and equally the difference in the median pain score between males and females was not significant. The distribution of current LBP by site is presented in table 4 . A total of 57 subjects (81.4\%) out of 70 physical therapists with work-related LBP reported having current back pain at the time of completing the questionnaire. Subjects with and without LBP reported the current pain mainly at low back and buttocks.

\section{Discussion}

The lifetime and point prevalence of work-related LBP among physical therapists in Kuwait are high and may be due to the nature of the occupation. The occupational hazards and job factors that include lifting or transferring dependent patients, age and gender of physical therapist, 
Table 4. Location of current LBP among physical therapists (n, \%)

\begin{tabular}{|c|c|c|c|}
\hline Location & $\begin{array}{l}M \\
(n=18)\end{array}$ & $\begin{array}{l}\mathrm{F} \\
(\mathrm{n}=39)\end{array}$ & $\begin{array}{l}\text { Total } \\
(\mathrm{n}=57)\end{array}$ \\
\hline Low back & $8(44.4)$ & $14(35.8)$ & $22(38.5)$ \\
\hline Low back and buttocks & $8(44.4)$ & $23(58.9)$ & $31(54.3)$ \\
\hline Shank & $2(11.1)$ & $2(5.1)$ & $4(7.0)$ \\
\hline
\end{tabular}

work setting and specialty could account for the high prevalence. The findings of this study are similar to those reported among physical therapists in Great Britain [12], Canada [13] and USA [14, 17]. More than half of the LBP injuries occurred within the first 5 years of work, probably due to improper body mechanics and faulty techniques during the daily activities of handling patients.

In the present study, female physical therapists reported higher rate of LBP than males, a finding similar to that of Bork et al. [17], probably due to weight and size of the female physical therapist. In general females have smaller body build than males, which apparently is a physical disadvantage when lifting or transferring larger patients. Equally important is the fact that some of the females were pregnant and the stress associated with pregnancy could have contributed to the LBP recorded by the female physical therapist. However, Mierzejewski et al. [13] did not observe any gender difference in LBP. In this study, working in orthopedics specialty (table 2) accounted for a majority of work-related LBP (34\%) and more females $(37 \%)$ than males $(28 \%)$ worked in orthope- dics. Apparently specialty is a contributing factor to workrelated LBP among physical therapists in Kuwait. The majority of physical therapists (86\%) (table 3) reported LBP injury while working in hospitals, probably due to the fact that the patients in the hospitals are less independent and require more care (lifting and transferring patients). This finding is consistent with other reports [12, 13]. LBP had a clear effect on daily activities thereby resulting in decreased non-work-related activities, sick leaves, and decreased number of working hours and even some therapists changing their work setting (table 3 ).

The prevalence of work-related LBP reported in the present study is higher than that reported among nurses $[15,16]$, although in both professions lifting patients to and from bed or transferring patients is commonly performed. It would therefore seem that nurses were either better trained or acquired a more efficient method of performing these duties. The contributory roles of ergonomic factors, technique of carrying/lifting and the work environment to back injury need to be further evaluated for the risk of back injury. A long-term longitudinal cohort study is required to determine the etiology, risk factors and role of ergonomic factors of the working environment.

\section{Conclusion}

The finding shows that LBP is a common problem with a high work-related life and point prevalence among physical therapists in Kuwait.

\section{Appendix}

Questionnaire for the Study of LBP among Physical Therapists in Kuwait

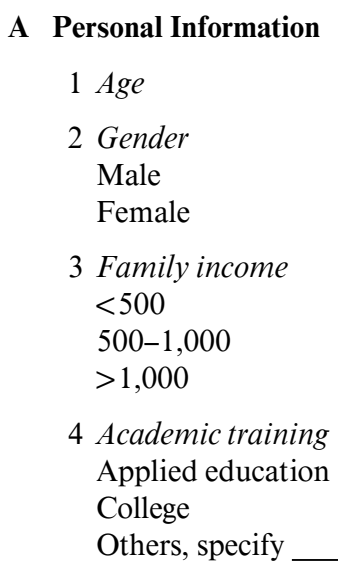

5 Medical disease before developing low back pain $(L B P)$
Hypertension
Diabetes mellitus
Cardiac diseases
Others, specify
6 Past medical treatment conditions
None
Antihypertensive
Hypoglycemic (oral, insulin)
Cardiac medications
Others, specify
7 Physical disability prior to developing $L B P$
None
Musculoskeletal
Neurological
Others, specify


Appendix (continued)

$\begin{array}{ll}8 \text { Area of specialty } & \\ \text { Neurology } & \text { Orthopedics } \\ \text { Cardiology } & \text { Geriatrics } \\ \text { Burns/plastics } \quad \text { Pediatrics } & \\ \text { General practice } \quad \text { Home care } & \\ \text { Others, specify } & \\ 9 \text { Years of experience as a physical therapist (in years) } \\ 10 \text { Work setting } \\ \text { General hospital } \\ \text { Private clinic } \\ \text { Private hospital } \\ \text { Special schools } \\ \text { Community care } \\ \text { Rehabilitation hospital } \\ 11 \text { Duration of the current work setting (in years) } \\ 12 \text { Nature of job } \\ \text { Full-time physical therapist } \\ \text { Part-time } \\ 13 \text { Number of hours of direct patient contact per week }\end{array}$

B Low Back Pain (LBP)

14 Before working as a physical therapist what type of LBP did you suffer?

None

Mild

Moderate

Severe

15 Before working as a physical therapist what type of functional limitations did you experience as a result of $L B P$ ?

None

Mild

Moderate

Severe

\section{Work-Related LBP}

16 Did you have LBP during your work as a physical therapist? No

Yes

If yes

17 During work as physical therapist what type of LBP have you experienced?

None

Mild

Moderate

Severe

18 Onset of pain/injury

Acute (sudden)

Chronic (gradual)

19 Average duration of pain in days during LBP episode

1 week

2-4 weeks

$>4$ weeks
20 Work setting in which injury occurred

Hospital University

Private Community care

Special school

21 Have you been affected by LBP from doing your regular activities?

No

Yes

22 Were you able to practice your regular activities during pain/ injury (e.g. bending, bending and twisting, stooping)?

No

Lifting, carrying

Pulling, pushing

Patient handling

Prolonged sitting

Prolonged standing

23 What limitations did you have due to LBP related to work as a physical therapist?

Sick leave

Compensation

Reduced non-work activities

Reduced number of working hours

Change of work setting

Others specify

24 Are you currently (presently) experiencing LBP?

No

Yes

25 Mark the location of pain on body diagram

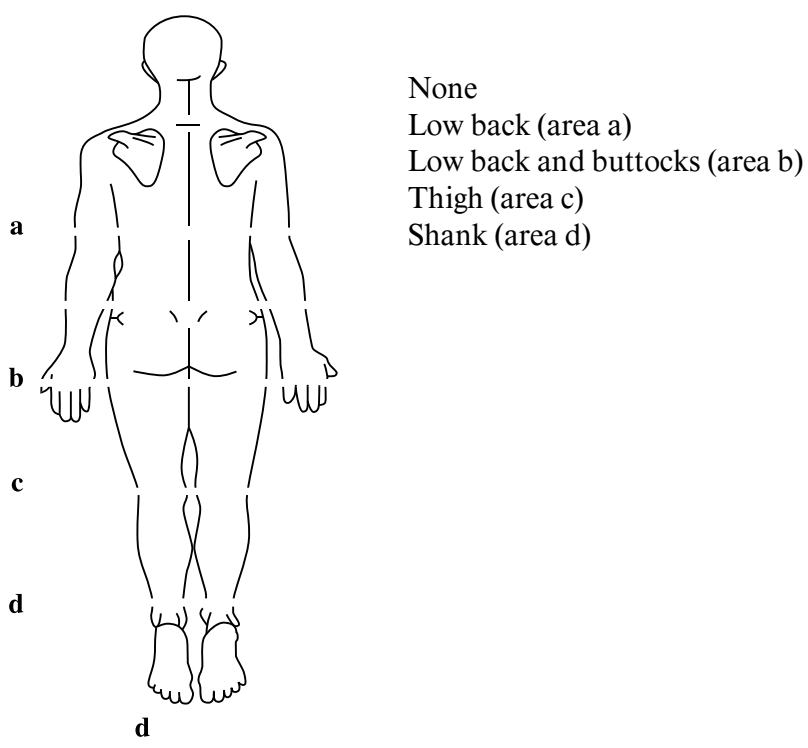

26 Rating (score of pain)

\begin{tabular}{lr}
\hline \\
No pain & 10 \\
Maximum pain
\end{tabular}




\section{References}

1 Nachemison A: Low back pain: Its etiology and treatment. Clin Med 1971;78:18-24.

2 Horal J: The clinical appearance of low back disorders in the city of Gothenburg, Sweden. Acta Orthop Scand Suppl 1969;118:8-73.

3 Frymoyer JW, Pope MH, Costanza MC, Rosen JC, Goggen JE, Wilder DG: Epidemiologic studies of low back pain. Spine 1980;5:419_ 423.

4 Kelsey J, White A: Epidemiology and impact of low back pain. Spine 1980;5:133-142.

5 Biering-Sorensen F: A prospective study of low back pain in a general population: Occurrence, recurrence, aetiology. Scand J Rehabil Med 1983;15:71-79.

6 Skovron ML: Epidemiology of low back pain. Baillieres Clin Rheumatol 1992;6:559-573.
7 Leboeuf-Yde C, Klougart N, Lauritzen T: How common is low back pain in Nordic population? Spine 1996;21:1518-1525.

8 Reigo T, Timpka T, Tropp H: The epidemiology of back pain in vocational age groups. Scand Primary Health Care Suppl 1999;17:16-21.

9 Kumar S: Cumulative load as a risk factor for back pain. Spine 1990;15:1311-1316.

10 Magora A: Investigation of the relation between low back pain and occupation. III. Physical requirements, sitting, standing and weight lifting. IMS Indian Med Surg 1972;41:5-9.

11 VidemanT, Nurminen T, Tola S: Low back pain in nurses and some loading factors of work. Spine 1984;9:400-404.

12 Scholey M, Hair MD: Back pain in physiotherapists involved in back care education. Ergonomics 1989;32:179-190.

13 Mierzejewski M, Kumar S: Prevalence of low back pain among physical therapists in Edmonton, Canada. Disabil Rehabil 1997;19:309_ 317.
14 Molumphy M, Unger B, Jenson GM, Lopopolo $\mathrm{RB}$ : Incidence of work-related low back pain in physical therapists. Phys Ther 1985;65:482486.

15 Harber P, Billet E, Gutowski M: Occupational low back pain in hospital nurses. J Occup Med 1985;27:518-524.

16 Stubbs DA, Buckle PW, Hudson MP, Rivers PM, Worringham CJ: Back pain in the nursing profession. 1. Epidemiology and pilot methodology. Ergonomics 1983;26:755-765.

17 Bork BE, Cook TM, Rosecrance JC, Engelhardt KA, Thomason ME, Wauford IJ, Worley RK: Work-related musculoskeletal disorders among physical therapists. Phys Ther 1996;76: 827-835. 